\title{
Analysis of Malignant Melanoma Cell Lines Exposed to Hypoxia Reveals the Importance of PFKFB4 Overexpression for Disease Progression
}

\author{
SONIA E. TROJAN ${ }^{1}$, MONIKA PIWOWAR $^{2}$, BARBARA OSTROWSKA ${ }^{1}$, \\ PIOTR LAIDLER ${ }^{1 *}$ and KINGA A. KOCEMBA-PILARCZYK ${ }^{1 *}$ \\ ${ }^{1}$ Chair of Medical Biochemistry, ${ }^{2}$ Department of Bioinformatics and Telemedicine, \\ Faculty of Medicine, Jagiellonian University - Medical College, Cracow, Poland
}

\begin{abstract}
Background/Aim: Most melanomas develop in hypoxic conditions. Since hypoxia via HIF-1 induces glycolysis, a process essential for malignant melanoma growth/survival, the goal of this study was to analyze the influence of hypoxia on the expression of HIF-1 target genes involved in glucose metabolism. Materials and Methods: The response of melanoma cell lines to hypoxic conditions was analyzed by RT-PCR and western blotting. A Kaplan-Meier survival analysis for patients with high and low expression level of PFKFB4 was performed. Further analysis of patients' data was performed using the R/Bioconductor environment. Results: Induction of PFKFB4 gene expression can be considered a crucial mechanism behind glycolysis enhancement in hypoxic melanoma cells. Analysis of a publicly available database revealed that high PFKFB4 expression contributes to poor prognosis of melanoma patients. Conclusion: Currently available anti-melanoma therapeutic strategies may significantly benefit from agents targeting PFKFB4 activity.
\end{abstract}

The incidence of melanoma is relatively low, representing less than $5 \%$ of all skin cancers, nevertheless, its frequency has been increasing over the past decades. Moreover, advanced-stage melanoma is highly aggressive and invasive malignancy constitutes around $70 \%$ of skin cancer-related deaths (1-4).

Melanoma arises from skin pigment cells (melanocytes) located in the basal layer of epidermis that are responsible

\footnotetext{
*These Authors contributed equaly to this study.

Correspondence to: Kinga Kocemba-Pilarczyk, Ph.D., Chair of Medical Biochemistry, Faculty of Medicine, Jagiellonian University - Medical College, Cracow, Poland. Tel: +48 1242274 00, e-mail: kinga.kocemba@uj.edu.pl
}

Key Words: Hypoxia, HIF-1, malignant melanoma, PFKFB4. for melanin production. One of the major risk factors for melanoma is chronic sun exposure of the skin, leading to UV- induced melanocyte mutations, especially within NRAS, $B R A F$ and $c K I T$ protooncogenes (5). On the other hand, a considerable group of melanoma patients reports a family history of disease, pointing out the hereditary background of this highly lethal cancer, characterized predominantly by $B R A F$ mutations $(5,6)$. In general, mutations in the genes involved in proliferation, apoptosis, metabolism and cell cycle constitute the main cause of malignant melanoma transformations (5).

Although the genetic alterations in melanocytic DNA are crucial for melanoma development, emerging data highlight the significant role of the skin microenvironment in melanoma initiation and progression. Skin microenvironment is a structural and functional constellation composed of normal skin cells such as keratinocytes, fibroblasts, endothelial cells, melanocytes and cells of the immune system subjected to mutual interactions. Disruption of this homeostasis may promote the development of melanoma (7). Importantly, the inherent part of skin microenvironment is low oxygen partial pressure, deepening during cancer progression and promoting its development (8-11).

Notably, literature data indicate that $50-60 \%$ of locally advanced tumors, including melanomas are characterized by areas of hypoxia or even anoxia in which oxygen concentration ranges from 0.5 to $1.5 \% \mathrm{O}_{2}(8,9,12)$. In melanoma, hypoxia was observed to accelerate malignant transformation (13-16) and tumor development/progression (12, 16-19). Of note, oxygen-deprived environment also contributes to treatment resistance (20-25) and phenotype switching of melanoma cells $(26,27)$. All the alterations observed in hypoxic cells result from hypoxia-mediated gene expression changes, initiated mainly by the hypoxia-inducible factor-1 (HIF-1) transcription factor (stabilized in hypoxic conditions, below $2 \% \mathrm{O}_{2}$ ) (28). Among the HIF-1 target genes are those coding for glycolytic enzymes and glucose transporters, that allow for sufficient ATP 
production in oxygen-deprived environment. Notably, enhanced glycolysis has been recently reported as a pathway associated with resistance to adoptive $\mathrm{T}$ cell therapy in melanoma mouse model (29). Moreover, it has been shown that the attenuation of glycolysis is crucial in the response to BRAF inhibitors (BRAFi) as by in BRAF-i resistant melanomas a decrease of glucose breakdown induces cell death $(30,31)$. As most melanomas reside in a hypoxic environment, the glycolytic pathway seems to be constantly induced. In this paper, using melanoma cell lines as a model, the influence of hypoxia on the expression of glycolysis related genes was analyzed. Importantly, our study revealed that the PFKFB4 gene product, 6-Phosphofructo-2Kinase/Fructose-2,6-Biphosphatase 4 (PFKFB4), is the crucial enzyme enhancing the glycolysis in hypoxic melanomas, the overexpression of which is associated with the poor prognosis of melanoma patients.

\section{Materials and Methods}

Cell lines and cell culture. Two human melanoma cell lines representing different stages of tumor progression were studied: WM115 from vertical growth phase and its metastatic derivative WM266-4 line. Both cell lines were obtained from ESTDAB Melanoma Cell Bank (Tubingen, Germany) and were grown according to their recommendation. Reduced oxygen culture conditions $\left(1 \% \mathrm{O}_{2}\right.$ hypoxia) were obtained, as described previously (32).

RNA isolation and cDNA synthesis. Total amount of RNA was extracted from melanoma cells using RNeasy Plus Mini kit (Qiagen, Hilden, Germany). The concentration and purity of all isolated RNA samples were determined with the use of NanoDrop ND-1000 Spectrophotometer (NanoDrop Technologies, Wilmington, DE, USA). For each sample $125 \mathrm{ng}$ of RNA was used for reverse transcription. cDNA synthesis was carried out using NG dART RT kit (EURx, Gdansk, Poland) with oligo (dT)20 primer and dART reverse transcriptase, as described in the manufacturer's protocol (EURx).

Reverse transcription polymerase chain reaction (RT-PCR). PCR reaction was carried out using Color OptiTaq PCR Master Mix (2x) (EURx) according to the manufacturer's protocol. The PCR mixture contained $0.6 \mu \mathrm{l}$ of each $10 \mu \mathrm{M}$ primers (forward and reverse), $5 \mu \mathrm{l}$ of Color OptiTaq PCR Master Mix (2x) and $5 \mu$ of nuclease free deionized water. $1 \mu \mathrm{L}$ of cDNA was added to each PCR mixture. The cDNA was amplified using the MJ Research PTC-200 Thermal Cycler. PCR reaction started with initial denaturation for $5 \mathrm{~min}$ at $95^{\circ} \mathrm{C}$. Then the PCR conditions for 26 cycles were as followed: $30 \mathrm{sec}$ at $95^{\circ} \mathrm{C}, 30 \mathrm{sec}$ at $65^{\circ} \mathrm{C}(P F K F B 3)$ or $58^{\circ} \mathrm{C}$ (all other genes) and $30 \mathrm{sec}$ at $72^{\circ} \mathrm{C}$. The extension reaction was for $10 \mathrm{~min}$ at $72^{\circ} \mathrm{C}$. The PCR products were analyzed on $1.5 \% \mathrm{w} / \mathrm{v}$ agarose gels. Bands were normalized using HPRT1 to correct for differences in loading of the cDNAs samples.

Western Blot. Western-blot analysis was performed as described previously (32).

Patients and statistical analysis. The gene expression and survival data of 214 melanoma patients (GSE65904) were downloaded from the NCBI Gene Expression Omnibus (GEO), a public repository of microarray data (33). The data were analyzed in the $\mathrm{R}$ environment (34). A number of libraries as GEOquery (35), Affy (36), Limma (37) were used to analyze gene expression. Based on the expression level of $P F K F B 4$ gene, the patients were divided in three groups G1, G2 and G3 using R/Bioconductor environment and segmented library (38) for fitting the regression models in case of broken-line relationships. Using limma, an $\mathrm{R} /$ Biocondictor software package significantly up-regulated genes in the G3 group (with the highest PFKFB4 expression) in comparison to the G1 group (with the lowest PFKFB4 expression) were found. All the selected genes were submitted to the Database for Annotation, Visualization and Integrated Discovery (DAVID), and the Kyoto Encyclopedia of Genes and Genomes (KEGG). The survival curves were estimated by the Kaplan-Meier method and compared by Log-rank test in GraphPad Prism 5.01 (GraphPad Software, La Jolla, CA, USA).

\section{Results}

The response of melanoma cells to low oxygen concentrations at the protein level. In the first stage, to validate our experimental setup, the influence of hypoxic stimulation on two melanoma cell lines, WM115 and WM266-4, was investigated. Hypoxia induced accumulation of HIF-1 alpha subunit protein (Figure 1A). In order to determine whether HIF-1 accumulation triggers a transcriptional response, RTPCR assay was performed. The gene selected for this analysis, Carbonic Anhydrase IX (CAIX), has been shown to be a HIF1 target $(39,40)$ and its HIF-1-dependent regulation has been reported in malignant melanoma (12). Interestingly, according to the literature, expression of CAIX significantly contributes to progression of melanoma as CAIX seems to be crucial in adaptation of melanoma cells to extracellular acidosis $(41,42)$, accompanying hypoxia. Expression of CAIX in normoxic conditions was negligible in both analyzed cell lines (Figure 1B). However, hypoxia induced expression of $C A I X$ in WM115 and WM266-4 cells (Figure 1B).

Effect of low oxygen conditions on glycolytic gene expression in melanoma cell lines. Since glycolysis is the essential energyyielding process accelerated in low oxygen environment and glycolysis enhancement was found to be associated with worse clinical outcome (43), semi-quantitative RT-PCR was used to examine the effect of reduced oxygen culture conditions on the expression of HIF-1 target genes involved in glucose breakdown in melanoma cells. The panel of selected genes comprised of HK2 (Hexokinase 2), PFKFB3 (6-Phosphofructo2-Kinase/Fructose-2,6-Biphosphatase 3), PFKFB4 (6Phosphofructo-2-Kinase/Fructose-2,6-Biphosphatase 4), ALDO $A$ (Aldolase A), ENO1 (Enolase 1), PKM (Pyruvate kinase, muscle), $L D H A$ (Lactate Dehydrogenase A) and SLC2A1 (Solute carrier family 2 , facilitated glucose transporter member 1). All the genes were previously shown to be HIF-1 target genes (44) containing HRE (Hypoxia Response Elements) elements in their promoters $(39,45-52)$. As shown in Figure 2, in both cell lines the majority of analyzed genes had a high 
A

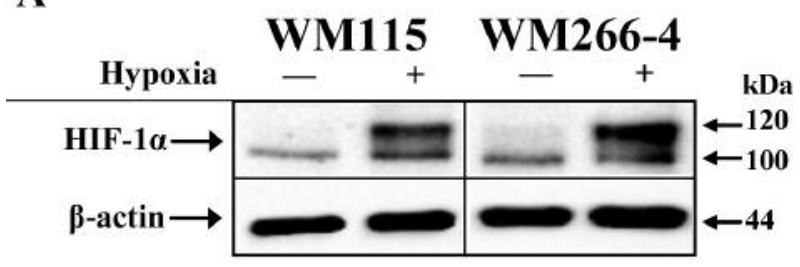

B

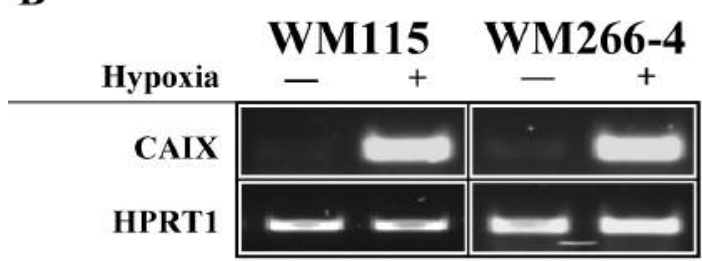

Figure 1. Response of WM115 and WM2264 melanoma cell lines to hypoxic conditions A) HIF-1 alpha accumulation in WM115 and WM266-4 melanoma cells. WM115 and WM266-4 cells were cultured for $24 \mathrm{~h}$ in normoxic or hypoxic $\left(24 \mathrm{~h}, 1 \% \mathrm{O}_{2}\right)$ conditions. HIF-1 alpha accumulation was detected using western blot. $\beta$-actin is shown as an internal control for equal protein loading. B) Expression of HIF-1 target gene, CAIX, in WM115 and WM2264 cell lines. WM115 and WM266-4 cells were cultured for $24 \mathrm{~h}$ in normoxic or hypoxic $\left(24 \mathrm{~h}, 1 \% \mathrm{O}_{2}\right)$ conditions. CAIX expression was detected by RT-PCR. HPRT1 is shown as an internal control for equal amount of cDNA.

expression in normoxic conditions indicating that HIF-1 is not the crucial transcription factor controlling their expression. The only gene, with low expression in normoxic conditions and clear induction in hypoxia was $P F K F B 4$, the one coding the cancer specific isoenzyme of phosphofructokinase II (PFK-II). In conclusion, these results indicate that, in contrast to the majority of studied genes encoding glycolytic enzymes, HIF-1 induced strong expression of PFKFB4.

PFKFB4 expression in melanoma cell lines and patients. The observation that the $P F K F B 4$ gene can be crucial for the enhancement of glycolytic pathway in melanoma cells under hypoxic conditions, prompted us to investigate its basal expression in a panel of melanoma cell lines. As shown in Figure 3, in WM793, 1205Lu, A375P, WM239A WM115 and WM266-4 cell lines the expression of $P F K F B 4$ was comparable under normoxic conditions., However, in WM35 and WM3211 the expression PFKFB4 was as high as in WM266-4 hypoxia treated cells. To determine if high expression of PFKFB4 is the consequence activation of HIF-1 pathway in normoxic conditions, in the same panel of cell lines, the expression of CAIX, the hallmark of active HIF-1 signaling in melanoma cells, was analyzed. Based on CAIX expression (Figure 3), which seems to be controlled exclusively by HIF-1 transcription factor in melanoma cell lines, it can be

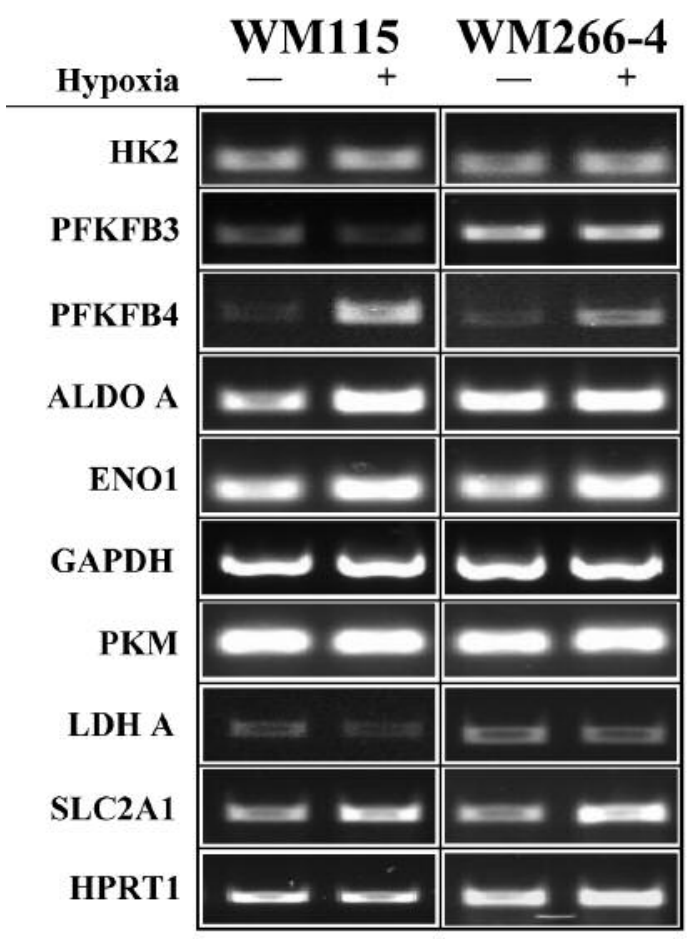

Figure 2. Expression of HIF-1 glycolytic target genes under reduced oxygen conditions in WM115 and WM2264 melanoma cell lines. The expression of HIF-1 glycolytic target genes HK2, PFKFB3, PFKFB4, ALDOA, ENO1, PDK1, PKM, LDHA, SLC2A1 in cells cultured for $24 \mathrm{~h}$ in normoxic or hypoxic $\left(24 \mathrm{~h}, 1 \% \mathrm{O}_{2}\right)$ conditions was determined by RT-PCR. HPRT1 is shown as an internal control for equal amount of cDNA.

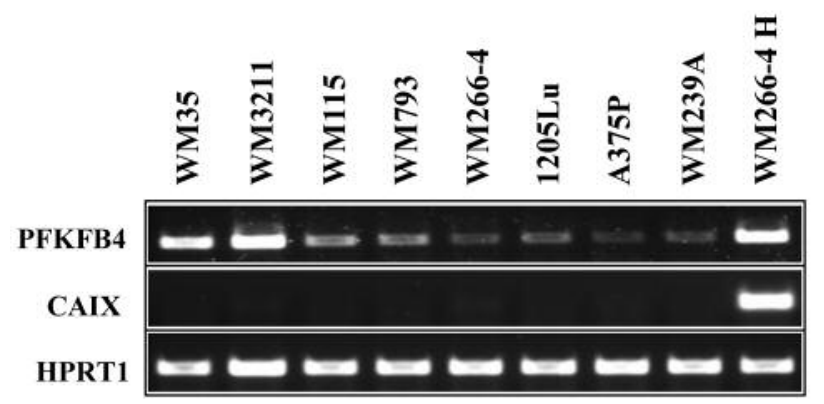

Figure 3. Basal expression of PFKFB4 and CAIX in the panel of human melanoma cell lines determined by RT-PCR. The expression PFKFB4 and CAIX was determined by RT-PCR. cDNA isolated from hypoxic WM266-4 (WM266-4H) was used to compare the basal normoxic expression of PFKFB4 and CAIX in melanoma cell lines with the expression level observed in hypoxic environment. HPRT1 is shown as an internal control for equal amount of cDNA.

concluded that there is a lack of HIF-1 activity in WM35 and WM3211. Thus, the high expression of PFKFB4 in WM35 and WM3211 is not a consequence of hypoxia- 
A

214 Malignant Melanoma Patients

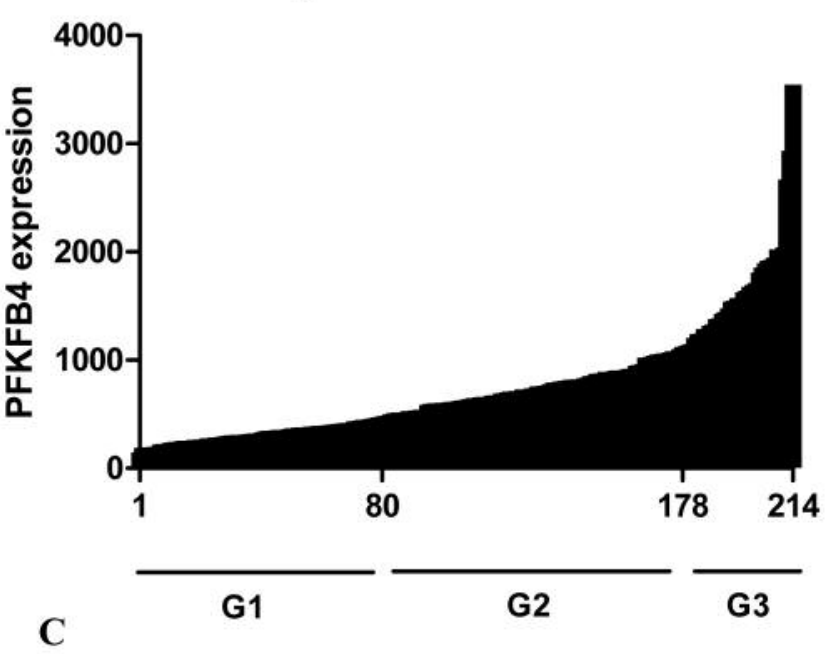

B

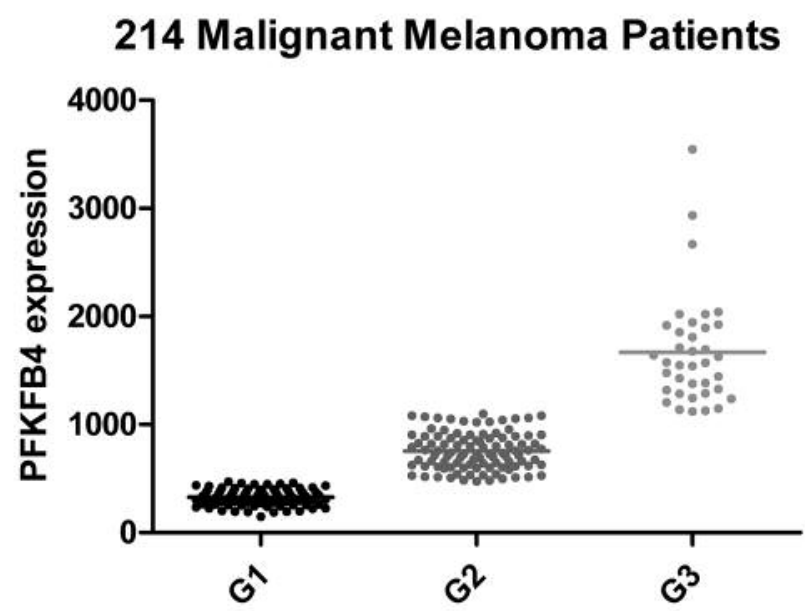

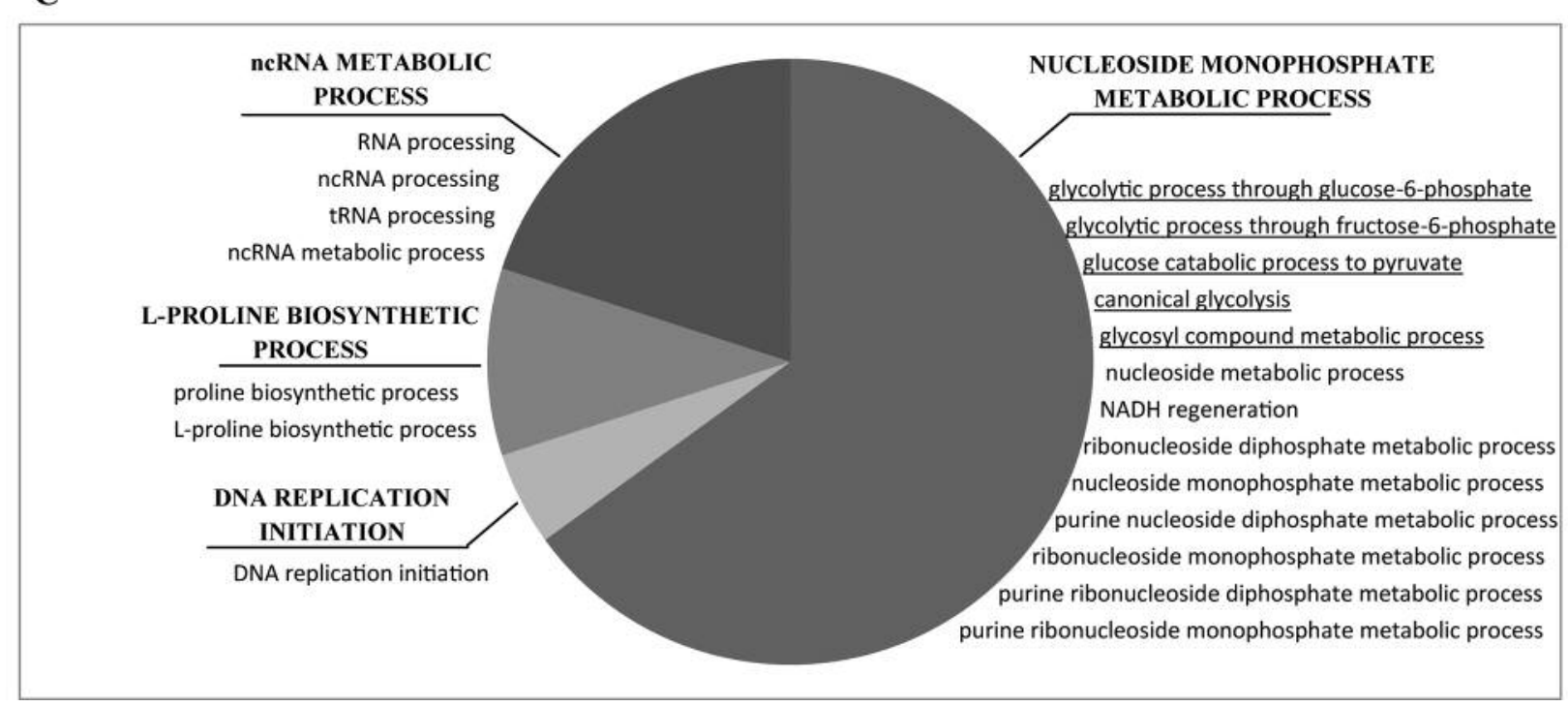

Figure 4. Analysis of PFKFB4 mRNA expression in malignant melanoma patients using a publicly available data set GSE65904. A) 214 malignant melanoma patients were classified in accordance to PFKFB4 mRNA expression. The patients were divided into three expression groups (G1, G2, G3) using the segmented regression available in R package (34). B) The PFKFB4 mRNA expression in G1, G2 and G3 groups; for subsequent gene expression comparison the three patients with the highest PFKFB4 were excluded from the analysis. C) Gene ontology processes with significant over-representation among the genes overexpressed (fold change $\geq 2$ ) in G3 in comparison to G1. Only the pathways having significant alterations $(p<0.05)$ are presented. The glycolysis related processes are underlined.

independent HIF-1 signaling in normoxic conditions, indicating that PFKFB4 can be expressed in melanoma cells also regardless of the presence of HIF-1 transcription factor. Next, the PFKFB4 mRNA expression was examined in melanoma patients using publicly available data set, GSE65904. As presented in Figure 4A, among malignant melanoma patients there was a group with high expression of PFKFB4 gene. Next, melanoma patients were divided, using segmented regression, in three groups $(\mathrm{G} 1, \mathrm{G} 2, \mathrm{G} 3)$ based on the expression level of PFKFB4 (Figure 4A and $B)$ and subsequently significantly up-regulated genes in the G3 group (with the highest PFKFB4 expression), in comparison to G1 group (with the lowest PFKFB4 expression), were identified. Annotation analysis performed on up-regulated genes with DAVID and KEGG showed that a significant number of up-regulated genes was involved in 
Distant metastasis free survival

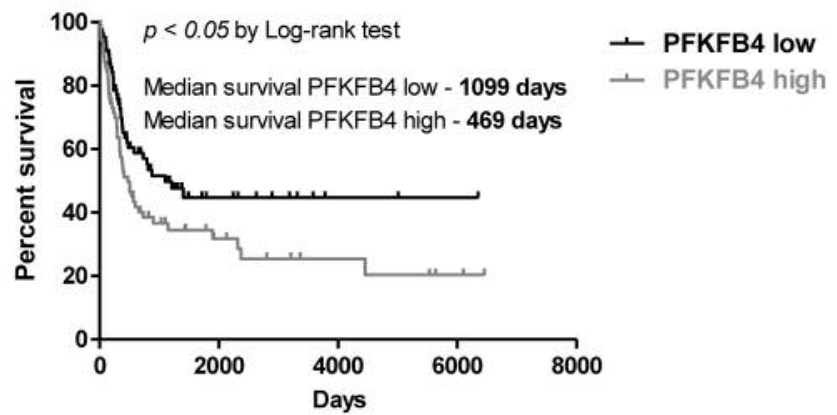

Overall survival

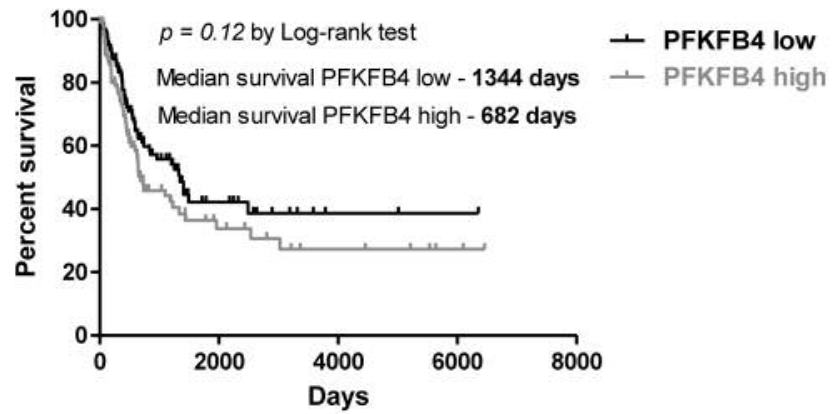

Distant metastasis free survival

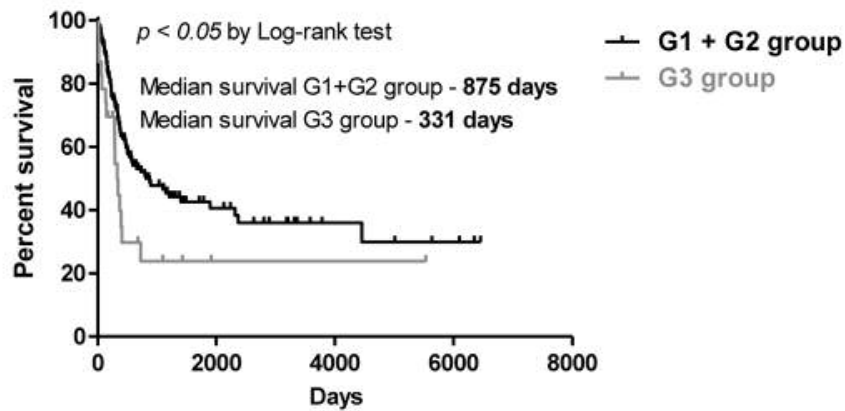

Overall survival

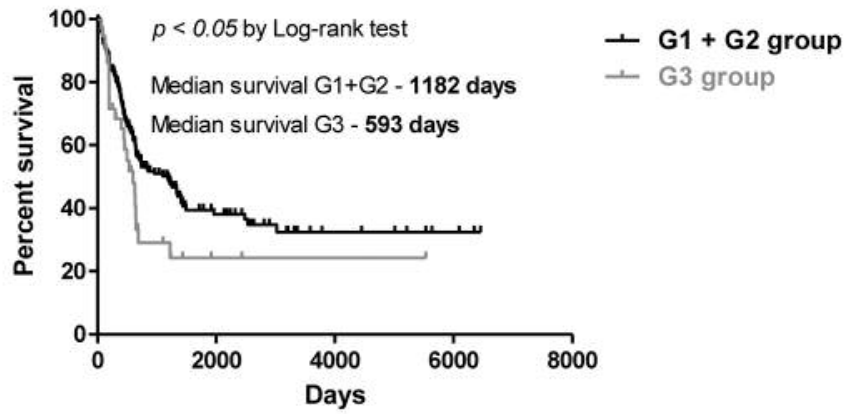

Figure 5. High PFKFB4 expression is associated with poor prognosis of melanoma patients. The publicly available micro-array data set GSE65904 was used to correlate PFKFB4 mRNA expression (median lowest, median highest, and G3 versus G1+G2) to disease outcome. Kaplan-Meier curves are presented for distant metastasis free survival (upper panel) and overall survival (lower panel). The median survival for the compared groups is given in the graphs. High PFKFB4 expression is associated with worse distant metastasis free survival and overall survival, $p<0.05$, by Log-rank test.

glucose breakdown (Figure 4C). These data clearly indicate that the group of patients with the highest PFKFB4 expression can be considered as the one with high rate of glucose breakdown. Taking into consideration the importance of glycolysis in the progression of melanoma, the melanoma patients were divided in groups based on the PFKFB4 expression (median lowest, median highest, and $\mathrm{G} 3$ versus $\mathrm{G} 1+\mathrm{G} 2$ ) and comparison of distant metastasis free and overall survival between groups was performed. As shown in Figure 5 (upper panel), the group with high PFKFB4 expression selected based on the median and PFKFB4 high group, identified by segmented regression (G3 group), showed significantly worse distant metastasis free survival, clearly indicating that cancer specific isoenzyme of phosphofructokinase II, PFKFB4, can have an important impact on the progression of malignant melanoma. As for the overall survival (Figure 5, lower panel), in the PFKFB4 high group identified based on the median expression the trend for the worse overall survival was clearly visible, whereas the G3 group had significantly worse OS survival in comparison to $\mathrm{G} 1+\mathrm{G} 2$ group.

\section{Discussion}

In this study we focused on the influence of hypoxia on the expression of genes involved in glucose metabolism in melanoma cells. Hypoxia occurs/appears when oxygen supply fails to meet demands of the body tissue and is a common phenomenon in advanced solid tumors (53) including most melanomas. Tumor hypoxia and HIFs affect most of the cancer hallmarks including: cell survival, vascularization, metabolism reprogramming, immune response, invasion, treatment resistance, metastasis, apoptosis and genomic instability (54-56). Our study revealed that many of analyzed HIF-1 target genes, which code for proteins involved in glucose metabolism had high basal normoxic expression indicating high glycolytic profile of melanoma cells at normoxic conditions. On the other hand, expression of certain genes involved in glucose metabolism was not apparently induced in hypoxic conditions in the studied cell lines. Interestingly, however, in both studied cell lines, very strong induction of PFKFB4 gene, which codes for cancer specific isoenzyme modulating glycolysis - phosphofructokinase II 
(PFK-II)/fructose-2,6-bisphosphatase (FBPase-II), was observed. The product of its kinase domain, Fru-2,6- $\mathrm{P}_{2}$, constitutes an essential activator of the glycolytic flux, activating glucose breakdown through allosteric modulation of the rate-limiting enzyme of glycolysis, phosphofructokinase I (PFK-I) $(57,58)$. As mentioned above, the protein coded by PFKFB4 gene is not a bona fide glycolytic enzyme, but its activity is associated with carcinogenesis and significantly enhances the rate of glucose breakdown. The fact that its basal normoxic expression is rather low (at least in most studied melanoma cell lines) suggests that HIF-1 mediated PFKFB4 induction can be considered as a universal mechanism for enhancement of hypoxia-mediated glucose breakdown in malignant melanoma. Although our data stays in line with studies conducted by Buart et al. (59), who indicated PFKFB4 gene as the one belonging to hypoxic signature in melanoma, our cell line analysis pointed that its expression is not restricted to hypoxic environment. The fact that there are melanoma cell lines with high PFKFB4 expression in normoxic conditions irrespective of active HIF-1 signaling suggests that in melanoma patients high basal PFKFB4 expression cannot be considered a direct hallmark of hypoxia. Important for deciphering the role of PFKFB4 in melanoma behavior/biology were the findings that came from the study of publicly available data set, revealing that its high expression significantly correlates with shorter overall survival of malignant melanoma patients.

Taking into consideration that melanoma cells mostly reside in hypoxic conditions and high glycolytic rate is involved in the resistance to BRAF inhibitors and adoptive T cell therapy (29), PFKFB4 seems to be an important gene, the function/significance of which should be subjected to further detailed study, especially in the context of antimelanoma treatment.

According to our knowledge, this is the first study showing the impact of PFKFB4 overexpression in the progression of malignant melanoma. In addition, we found that in patients with high PFKFB4 gene expression there was an up-regulation of genes involved in glucose metabolism. Altogether our data indicate that phosphofructokinase II isoenzyme 4, coded by PFKFB4 gene, may become a novel target in anti-melanoma therapeutic strategies and inhibition of its activity may significantly improve the outcome of currently applied therapies against malignant melanoma.

\section{Conflicts of Interest}

The Authors have no conflicts of interest to disclose.

\section{Acknowledgements}

The work presented in this paper was supported by a grant from the National Committee for Scientific Research with nr K/DSC/005285.

\section{References}

1 Rastrelli M, Tropea S, Rossi CR and Alaibac M: Melanoma: Epidemiology, risk factors, pathogenesis, diagnosis and classification. In Vivo 28(6): 1005-1011, 2014.

2 MacKie RM, Hauschild A and Eggermont AM: Epidemiology of invasive cutaneous melanoma. Ann Oncol 20(Suppl 6): vi1-7, 2009.

3 Matta AS: Melanoma and hypoxia melanoma is an aggressive skin tumor. J Pigment Disord 2: 9, 2015.

4 Kosmidis C, Baka S, Sapalidis K, Mixalopoulos N, Atmatzidis S, Koulouris H, Anthimidis G, Varsamis N, Zarogoulidis P, Man Y, Georgakoudi E, Mantalovas S, Koimtzis G, Tsakalidis A and Kesisoglou I: Melanoma from molecular pathways to clinical treatment: An up to date review. J Biomed 2: 94-100, 2017.

5 Shain $\mathrm{AH}$ and Bastian BC: From melanocytes to melanomas. Nat Rev Cancer 16(6): 345-358, 2016.

6 Soura E, Eliades PJ, Shannon K, Stratigos AJ and Tsao H: Hereditary melanoma: Update on syndromes and management: Genetics of familial atypical multiple mole melanoma syndrome. J Am Acad Dermatol 74(3): 395-407; quiz 408-310, 2016.

7 Olbryt M: Role of tumor microenvironment in the formation and progression of skin melanoma. Postepy Hig Med Dosw (Online) 67: 413-432, 2013.

8 Vaupel P, Kallinowski F and Okunieff P: Blood flow, oxygen and nutrient supply, and metabolic microenvironment of human tumors: A review. Cancer Res 49(23): 6449-6465, 1989.

9 Lartigau E, Randrianarivelo H, Avril MF, Margulis A, Spatz A, Eschwege $\mathrm{F}$ and Guichard $\mathrm{M}$ : Intratumoral oxygen tension in metastatic melanoma. Melanoma Res 7(5): 400-406, 1997.

10 Evans SM, Schrlau AE, Chalian AA, Zhang P and Koch CJ: Oxygen levels in normal and previously irradiated human skin as assessed by ef5 binding. J Invest Dermatol 126(12): 25962606, 2006.

11 Carreau A, El Hafny-Rahbi B, Matejuk A, Grillon C and Kieda $\mathrm{C}$ : Why is the partial oxygen pressure of human tissues a crucial parameter? Small molecules and hypoxia. J Cell Mol Med 15(6): 1239-1253, 2011.

12 Bedogni B and Powell MB: Hypoxia, melanocytes and melanoma - survival and tumor development in the permissive microenvironment of the skin. Pigment Cell Melanoma Res 22(2): 166-174, 2009.

13 Bedogni B, Welford SM, Cassarino DS, Nickoloff BJ, Giaccia $\mathrm{AJ}$ and Powell MB: The hypoxic microenvironment of the skin contributes to akt-mediated melanocyte transformation. Cancer Cell 8(6): 443-454, 2005.

14 Monsel G, Ortonne N, Bagot M, Bensussan A and Dumaz N: Ckit mutants require hypoxia-inducible factor 1alpha to transform melanocytes. Oncogene 29(2): 227-236, 2010.

15 Hanna SC, Krishnan B, Bailey ST, Moschos SJ, Kuan PF, Shimamura T, Osborne LD, Siegel MB, Duncan LM, O'Brien ET, 3rd, Superfine R, Miller CR, Simon MC, Wong KK and Kim WY: Hiflalpha and hif2alpha independently activate src to promote melanoma metastases. J Clin Invest 123(5): 2078-2093, 2013.

16 Huber R, Meier B, Otsuka A, Fenini G, Satoh T, Gehrke S, Widmer D, Levesque MP, Mangana J, Kerl K, Gebhardt C, Fujii $\mathrm{H}$, Nakashima C, Nonomura Y, Kabashima K, Dummer R, Contassot E and French LE: Tumour hypoxia promotes melanoma growth and metastasis via high mobility group box-1 and m2-like macrophages. Sci Rep 6: 29914, 2016. 
17 Homsi J, Cubitt CL, Zhang S, Munster PN, Yu H, Sullivan DM, Jove R, Messina JL and Daud AI: Src activation in melanoma and src inhibitors as therapeutic agents in melanoma. Melanoma Res 19(3): 167-175, 2009.

18 Asnaghi L, Lin MH, Lim KS, Lim KJ, Tripathy A, Wendeborn M, Merbs SL, Handa JT, Sodhi A, Bar EE and Eberhart CG: Hypoxia promotes uveal melanoma invasion through enhanced notch and mapk activation. PLoS One 9(8): e105372, 2014.

19 Craig EA, Weber JD and Spiegelman VS: Involvement of the mrna binding protein crd-bp in the regulation of metastatic melanoma cell proliferation and invasion by hypoxia. J Cell Sci 125(Pt 24): 5950-5954, 2012.

20 Lenggenhager D, Curioni-Fontecedro A, Storz M, Shakhova O, Sommer L, Widmer DS, Seifert B, Moch H, Dummer R and MihicProbst D: An aggressive hypoxia related subpopulation of melanoma cells is trp-2 negative. Transl Oncol 7(2): 206-212, 2014.

21 Warfel NA and El-Deiry WS: Hif-1 signaling in drug resistance to chemotherapy. Curr Med Chem 21(26): 3021-3028, 2014.

22 Elcheva I, Tarapore RS, Bhatia $\mathrm{N}$ and Spiegelman VS: Overexpression of mrna-binding protein crd-bp in malignant melanomas. Oncogene 27(37): 5069-5074, 2008.

23 Qin Y, Roszik J, Chattopadhyay C, Hashimoto Y, Liu C, Cooper ZA, Wargo JA, Hwu P, Ekmekcioglu $\mathrm{S}$ and Grimm EA: Hypoxia-driven mechanism of vemurafenib resistance in melanoma. Mol Cancer Ther 15(10): 2442-2454, 2016.

24 Pucciarelli D, Lengger N, Takacova M, Csaderova L, Bartosova M, Breiteneder H, Pastorekova S and Hafner C: Hypoxia increases the heterogeneity of melanoma cell populations and affects the response to vemurafenib. Mol Med Rep 13(4): 3281-3288, 2016.

$25 \mathrm{Li} \mathrm{H}$, Chen J, Wang X, He M, Zhang Z and Cen Y: Nodal induced by hypoxia exposure contributes to dacarbazine resistance and the maintenance of stemness in melanoma cancer stemlike cells. Oncol Rep 39(6): 2855-2864, 2018.

26 O'Connell MP and Weeraratna AT: Change is in the air: The hypoxic induction of phenotype switching in melanoma. J Invest Dermatol 133(10): 2316-2317, 2013.

27 Widmer DS, Hoek KS, Cheng PF, Eichhoff OM, Biedermann T, Raaijmakers MIG, Hemmi S, Dummer R and Levesque MP: Hypoxia contributes to melanoma heterogeneity by triggering hif 1alpha-dependent phenotype switching. J Invest Dermatol 133(10): 2436-2443, 2013.

28 Bracken CP, Fedele AO, Linke S, Balrak W, Lisy K, Whitelaw ML and Peet DJ: Cell-specific regulation of hypoxia-inducible factor (hif)-1alpha and hif-2alpha stabilization and transactivation in a graded oxygen environment. J Biol Chem 281(32): 22575-22585, 2006.

29 Cascone T, McKenzie JA, Mbofung RM, Punt S, Wang Z, Xu C, Williams LJ, Bristow CA, Carugo A, Peoples MD, Li L, Karpinets T, Huang L, Malu S, Creasy C, Leahey SE, Chen J, Chen Y, Pelicano H, Bernatchez C, Gopal YNV, Heffernan TP, Hu J, Wang J, Amaria RN, Garraway LA, Huang P, Yang P, Wistuba, II, Woodman SE, Roszik J, Davis RE, Davies MA, Heymach JV, Hwu P and Peng W: Increased tumor glycolysis characterizes immune resistance to adoptive $\mathrm{t}$ cell therapy. Cell Metab 27(5): 977-987 e974, 2018.

30 Parmenter TJ, Kleinschmidt M, Kinross KM, Bond ST, Li J, Kaadige MR, Rao A, Sheppard KE, Hugo W, Pupo GM, Pearson RB, McGee SL, Long GV, Scolyer RA, Rizos H, Lo RS, Cullinane C, Ayer DE, Ribas A, Johnstone RW, Hicks RJ and McArthur GA: Response of braf-mutant melanoma to braf inhibition is mediated by a network of transcriptional regulators of glycolysis. Cancer Discov 4(4): 423-433, 2014.

31 Paluncic J, Kovacevic Z, Jansson PJ, Kalinowski D, Merlot AM, Huang ML, Lok HC, Sahni S, Lane DJ and Richardson DR: Roads to melanoma: Key pathways and emerging players in melanoma progression and oncogenic signaling. Biochim Biophys Acta 1863(4): 770-784, 2016.

32 Kocemba-Pilarczyk KA, Ostrowska B, Trojan S, Aslan E, Kusior D, Lasota M, Lenouvel C and Dulinska-Litewka J: Targeting the hypoxia pathway in malignant plasma cells by using 17allylamino-17-demethoxygeldanamycin. Acta Biochim Pol 65(1): 101-109, 2018.

33 Edgar R, Domrachev $M$ and Lash AE: Gene expression omnibus: Ncbi gene expression and hybridization array data repository. Nucleic Acids Res 30(1): 207-210, 2002.

34 R Core Team: R: A language and environment for statistical computing. R Foundation for Statistical Computing, Vienna, Austria, 2016.

35 Davis S and Meltzer PS: Geoquery: A bridge between the gene expression omnibus (geo) and bioconductor. Bioinformatics 23(14): 1846-1847, 2007.

36 Gautier L, Cope L, Bolstad BM and Irizarry RA: Affy--analysis of affymetrix genechip data at the probe level. Bioinformatics 20(3): 307-315, 2004.

37 Ritchie ME, Phipson B, Wu D, Hu Y, Law CW, Shi W and Smyth GK: Limma powers differential expression analyses for rna-sequencing and microarray studies. Nucleic Acids Res 43(7): e47, 2015.

38 Muggeo VMR: Segmented: An r package to fit regress models with broken-line relationships. R News 8(1): 20-25, 2008.

39 Potter C and Harris AL: Hypoxia inducible carbonic anhydrase ix, marker of tumour hypoxia, survival pathway and therapy target. Cell Cycle 3(2): 164-167, 2004.

40 Kaluz S, Kaluzova M, Liao SY, Lerman M and Stanbridge EJ: Transcriptional control of the tumor- and hypoxia-marker carbonic anhydrase 9: A one transcription factor (hif-1) show? Biochim Biophys Acta 1795(2): 162-172, 2009.

41 Andreucci E, Peppicelli S, Carta F, Brisotto G, Biscontin E, Ruzzolini J, Bianchini F, Biagioni A, Supuran CT and Calorini L: Carbonic anhydrase ix inhibition affects viability of cancer cells adapted to extracellular acidosis. J Mol Med (Berl) 95(12): 1341-1353, 2017.

42 Federici C, Lugini L, Marino ML, Carta F, Iessi E, Azzarito T, Supuran CT and Fais S: Lansoprazole and carbonic anhydrase ix inhibitors sinergize against human melanoma cells. J Enzyme Inhib Med Chem 31(sup1): 119-125, 2016.

43 Falkenius J, Lundeberg J, Johansson H, Tuominen R, Frostvik-Stolt M, Hansson J and Egyhazi Brage S: High expression of glycolytic and pigment proteins is associated with worse clinical outcome in stage iii melanoma. Melanoma Res 23(6): 452-460, 2013.

44 Golinska M, Troy H, Chung YL, McSheehy PM, Mayr M, Yin X, Ly L, Williams KJ, Airley RE, Harris AL, Latigo J, Perumal M, Aboagye EO, Perrett D, Stubbs $M$ and Griffiths JR: Adaptation to hif-1 deficiency by upregulation of the amp/atp ratio and phosphofructokinase activation in hepatomas. BMC Cancer 11: 198, 2011.

45 Luo W, Hu H, Chang R, Zhong J, Knabel M, O'Meally R, Cole RN, Pandey A and Semenza GL: Pyruvate kinase $\mathrm{m} 2$ is a phd3stimulated coactivator for hypoxia-inducible factor 1 . Cell 145(5): 732-744, 2011. 
46 Semenza GL, Jiang BH, Leung SW, Passantino R, Concordet JP, Maire $\mathrm{P}$ and Giallongo A: Hypoxia response elements in the aldolase a, enolase 1 , and lactate dehydrogenase a gene promoters contain essential binding sites for hypoxia-inducible factor 1. J Biol Chem 271(51): 32529-32537, 1996.

47 Minchenko O, Opentanova I, Minchenko D, Ogura T and Esumi $\mathrm{H}$ : Hypoxia induces transcription of 6-phosphofructo-2kinase/fructose-2,6-biphosphatase-4 gene via hypoxia-inducible factor-1alpha activation. FEBS Lett 576(1-2): 14-20, 2004.

48 Obach M, Navarro-Sabate A, Caro J, Kong X, Duran J, Gomez M, Perales JC, Ventura F, Rosa JL and Bartrons R: 6-phosphofructo2-kinase (pfkfb3) gene promoter contains hypoxia-inducible factor1 binding sites necessary for transactivation in response to hypoxia. J Biol Chem 279(51): 53562-53570, 2004.

49 Lee HG, Kim H, Son T, Jeong Y, Kim SU, Dong SM, Park YN, Lee JD, Lee JM and Park JH: Regulation of hk2 expression through alterations in cpg methylation of the hk2 promoter during progression of hepatocellular carcinoma. Oncotarget 7(27): 41798-41810, 2016.

50 Hayashi M, Sakata M, Takeda T, Yamamoto T, Okamoto Y, Sawada K, Kimura A, Minekawa R, Tahara M, Tasaka K and Murata Y: Induction of glucose transporter 1 expression through hypoxia-inducible factor 1alpha under hypoxic conditions in trophoblast-derived cells. J Endocrinol 183(1): 145-154, 2004.

$51 \mathrm{Lu} \mathrm{S}, \mathrm{Gu}$ X, Hoestje S and Epner DE: Identification of an additional hypoxia responsive element in the glyceraldehyde-3phosphate dehydrogenase gene promoter. Biochim Biophys Acta 1574(2): 152-156, 2002.

52 Graven KK, Yu Q, Pan D, Roncarati JS and Farber HW: Identification of an oxygen responsive enhancer element in the glyceraldehyde-3-phosphate dehydrogenase gene. Biochim Biophys Acta 1447(2-3): 208-218, 1999.
53 Muz B, de la Puente P, Azab F and Azab AK: The role of hypoxia in cancer progression, angiogenesis, metastasis, and resistance to therapy. Hypoxia (Auckl) 3: 83-92, 2015.

54 Wigerup C, Pahlman S and Bexell D: Therapeutic targeting of hypoxia and hypoxia-inducible factors in cancer. Pharmacol Ther 164: 152-169, 2016

55 Sormendi S and Wielockx B: Hypoxia pathway proteins as central mediators of metabolism in the tumor cells and their microenvironment. Front Immunol 9: 40, 2018.

56 Arends J: Metabolism in cancer patients. Anticancer Res 30(5): 1863-1868, 2010.

57 Van Schaftingen E: Fructose 2,6-bisphosphate. Adv Enzymol Relat Areas Mol Biol 59: 315-395, 1987.

58 Hue L and Rider MH: Role of fructose 2,6-bisphosphate in the control of glycolysis in mammalian tissues. Biochem J 245(2): 313-324, 1987.

59 Buart S, Terry S, Noman MZ, Lanoy E, Boutros C, Fogel P, Dessen P, Meurice G, Gaston-Mathe Y, Vielh P, Roy S, Routier E, Marty V, Ferlicot S, Legres L, Bouchtaoui ME, Kamsu-Kom N, Muret J, Deutsch E, Eggermont A, Soria JC, Robert C and Chouaib S: Transcriptional response to hypoxic stress in melanoma and prognostic potential of gbe1 and bnip3. Oncotarget 8(65): 108786-108801, 2017.
Received October 23, 2018

Revised November 6, 2018

Accepted November 7, 2018 